\title{
Potencial de expansão e ocupação urbana no município de Timóteo - MG
}

\author{
Paula Márcia Brasil Garcia1, Frederico Garcia Sobreira² \& Ana Clara Mourão Moura ${ }^{3}$
}

\begin{abstract}
Resumo O Município de Timóteo localiza-se na porção leste do estado de Minas Gerais e faz parte da mesorregião Vale do Rio Doce e da microrregião Ipatinga. Está inserido na bacia Federal do Rio Doce e na bacia Estadual do Rio Piracicaba. Possui população de 79.092 habitantes (IBGE 2000) e uma área de $145.149 \mathrm{~km}^{2}$, sendo grande parte ocupada pelo Parque Estadual do Rio Doce, que possui uma área de 36.970 ha e abrange também parte dos municípios de Marliéria e Dionísio. A ocupação urbana no município de Timóteo atualmente configura-se como um problema, pois o município carece de áreas adequadas para expansão, sendo que um dos problemas relacionados a essa tônica é a ocupação desordenada nas áreas de influência do Parque do Rio Doce, comprometendo a preservação das mesmas. Ocorre também um grande número de ocupações em locais suscetíveis a acidentes geológicos. Por se tratar de uma região atrativa do ponto de vista econômico, o município tende a crescer cada vez mais, agravando os problemas de ocupação urbana. O trabalho consistiu no levantamento de áreas suscetíveis a deflagração de acidentes geológicos, identificação de áreas potenciais para ocupação urbana e uma reavaliação do zoneamento do Plano Diretor do município. Destaca-se neste trabalho a importância em se considerar o meio físico como determinante para realização do planejamento urbano não apenas para proposição de áreas para ocupação, mas também para se definir de forma clara áreas inadequadas para a mesma.
\end{abstract}

Palavras-chave: Ocupação urbana, áreas de risco, Plano Diretor.

\begin{abstract}
Potential of urban expansion and occupation in the city of Timóteo - MG. Timóteo located in the eastern of Minas Gerais and is part of Doce River Valley region and Ipatinga microregion. Is inserted in the Federal basin of River Doce and also in the Piracicaba's basin. It has population of 79,092 inhabitants (IBGE 2000) and an area of 145,149 $\mathrm{km}^{2}$, being largely occupied by the River Doce Park, wich has an area of 36.970 ha and also covers the cities of Marlieria e Dionísio. The urban occupation in the city of Timóteo currently appears as a problem because the city needs more appropriate areas for expantion, and one of the most important issue related to this question is the disordered occupation in the influence areas of Rio Doce Park. There is also a large number of occupations in locations close to areas susceptible to geological accidents. Because it is an attractive region economically, the city tends to grow more and more, aggravating the problems of urban occupation. This paper included a survey of areas susceptible to geological accidents, identifying potential areas for urban occupation and an assessment of the Master Plan of the Timóteo city. The highlight of this work was the importance of taking into account the geomorphology as a determinant for the performance of urban planning, not only to propose areas for occupation, but also to clearly define areas.
\end{abstract}

Keywords: Urban occupation, risk areas, Master Plan.

INTRODUÇÃo As características históricas de uso e ocupação do território regional do Vale do Aço, aliadas à exiguidade de terras, bem como à grande ocorrência de áreas íngremes inadequadas à ocupação humana e o tipo de atividade industrial predominante, são alguns dos fatores que contribuem diretamente para o surgimento de um tipo de organização territorial marcado por conflitos socioambientais e situações de risco e vulnerabilidade ambiental.

A ocupação urbana no município de Timóteo atualmente configura-se como um problema, pois o município carece de áreas adequadas para expansão, sendo que uma das questões relacionada a essa tônica é a ocupação desordenada nas áreas de influência do
Parque do Rio Doce, comprometendo a preservação das mesmas. Ocorre também um grande número de ocupações em locais próximos a áreas passíveis de erosão e escorregamentos, devidos não só a condicionantes antrópicos, mas também naturais. Por se tratar de uma região atrativa do ponto de vista econômico, o município tende a crescer cada vez mais, agravando os problemas da ocupação urbana. Como muitas questões relevantes do ponto de vista urbano-ambiental não foram contempladas do Plano Diretor do Município, isto pode agravar os problemas de ocupação oriundos da falta de planejamento. Assim, pretende-se com este estudo fornecer subsídios para avaliações urbano-ambientais de relevante interesse para o município de Timóteo, assim

1 - Departamento de Geologia, Universidade Federal de Ouro Preto, Ouro Preto (MG), Brasil. E-mail: paulabrasilgarcia@yahoo.com.br

2 - Departamento de Engenharia Ambiental, Universidade Federal de Ouro Preto, Ouro Preto (MG), Brasil. E-mail: sobreira@degeo.ufop.br 3 - Departamento de Arquitetura e Urbanismo, Universidade Federal de Minas Gerais, Belo Horizonte (MG), Brasil. E-mail: anaclaramoura@yahoo.com.br 
como definir os principais conflitos de uso e locais mais problemáticos do ponto de vista geológico e geomorfológico, além de produzir uma referência metodológica para estudos urbano-ambientais futuros.

HISTÓRICO DA OCUPAÇÃO O Município de Timóteo faz parte da mesorregião Vale do Rio Doce e da microrregião Ipatinga, na região leste de Minas Gerais (Fig. 1). O Município está inserido na bacia Estadual do Rio Piracicaba e dista 196 km de Belo Horizonte. Sua população é de 79.092 habitantes (IBGE 2000) e a área é de $145.149 \mathrm{~km}^{2}$ Grande parte do município de Timóteo é ocupada pelo Parque Estadual do Rio Doce, que ocupa uma área de 36.970 ha e abrange também parte dos municípios de Marliéria e Dionísio (IEF 2005).

A região do Vale do Aço teve sua origem em meados do século XIX, com os arraiais de São Sebastião do Alegre Timóteo e Santo Antônio do Piracicaba, que deu origem à cidade de Coronel Fabriciano (Costa 1995). Em 1903 foi iniciada a obra de construção da estrada de ferro Vitória-Minas. O período que antecedeu a industrialização da região teve um papel irrelevante no cenário econômico da região, uma vez que a população se localizava dispersa pelos campos ocupada com atividades de subsistência. Em 1937 foi inaugurada a Companhia Siderúrgica Belgo-Mineira no município de João Monlevade, o que deu início à concentração de indústrias nas proximidades da confluência dos rios Doce e Piracicaba. A ferrovia e a abundância de matas e minério de ferro foram fatores que contribuíram, em 1944, para a implantação de outra siderúrgica no então distrito de Timóteo - a Aços Especiais de Itabira - Acesita. Entre os anos de 1944 e 1951, a Acesita tornou-se proprietária de aproximadamente 4.153 ha, cerca de 2/3 da área do atual município de Timóteo. A transferência do eixo dessa economia regional do setor primário para o secundário, promovido pela Acesita, ganhou novo impulso com a chegada da Usiminas em 1956, no distrito de Ipatinga.

A implantação destas duas usinas siderúrgicas, assim como a produção da infraestrutura urbana necessária para o funcionamento das mesmas, transformou de forma intensa a economia agrária pré-existente da região. Assim, deu-se início uma redistribuição espacial da população, juntamente com modificações profundas na estrutura fundiária tendo por consequência uma

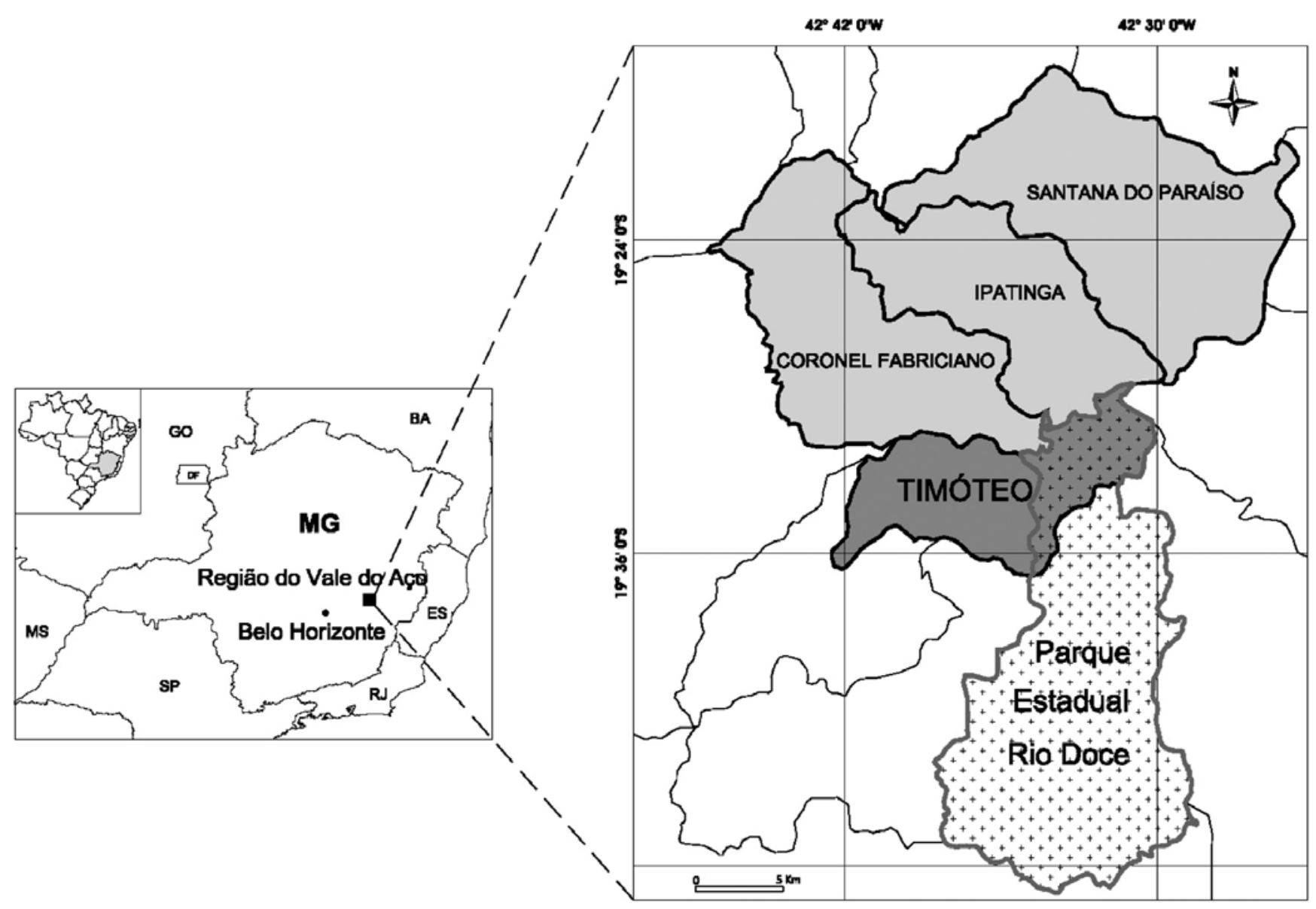

Figura 1 - Mapa de localização. 
expansão crescente da mancha urbana. Na década de 70 , foram instalados grandes projetos de reflorestamento por parte da Usiminas, instalação da Cenibra (Celulose Nipo-Brasileira) no município de Belo Oriente, expansão da pecuária e consolidação do Aglomerado Urbano do Vale do Aço (AUVA), formado pelo município original, Coronel Fabriciano e pelos dois municípios desmembrados nos anos 60: Ipatinga e Timóteo.

Em 2006 foi instituída a Região Metropolitana do Vale do Aço (RMVA), regida pela Lei Complementar $\mathrm{n}^{\circ} 90$ e sendo composta por quatro municípios: Ipatinga, Coronel Fabriciano, Timóteo e Santana do Paraíso. Na década de 1940, quando a usina Acesita foi instalada, o então distrito de Timóteo (que pertencia ao município de Coronel Fabriciano) começou seu processo de expansão urbana, com a criação de uma área urbana ao entorno da usina também chamada Acesita, prevista para abrigar cerca de 3.000 moradias. Cabe ressaltar que esta área urbana caracterizava-se por possuir a mesma hierarquia do interior da usina. Nas décadas de 1950 e 1960, impulsionado pelos empregos diretos e indiretos gerados pela usina, começou o processo de inversão do quadro ocupacional, com a população deixando de ser rural e passando a ser predominantemente urbana. Destaca-se que nestas décadas, a mata foi intensamente devastada para, num primeiro momento, servir de carvão vegetal para a usina e em seguida deu-se início ao reflorestamento empresarial. Assim, a expansão urbana no município de Timóteo, foi acompanhada pela devastação de florestas e o surgimento de áreas de ocupação desordenada.

Com o intuito de visualizar a evolução da mancha urbana num período de aproximadamente três décadas, foi realizada uma delimitação da área urbana de Timóteo nas datas de 1970, 1989 e 2004. Utilizou-se para esta delimitação a carta topográfica do IBGE 1970, na escala 1:100.000, ortofotos de 1989 (CEMIG, escala 1:10.000) e imagem de satélite Ikonos de 2004 (resolução de $1 \mathrm{~m}$ ). A figura 2 ilustra a expansão urbana do Município. A cidade expandiu-se em direção ao núcleo urbano da Acesita e também para oeste e leste. Destaca-se que a expansão urbana acarretou diversos impactos no meio físico natural do município. Devido à topografia acidentada da área, a população tendeu a se instalar, inicialmente, ao longo dos vales e nas áreas planas. Posteriormente, muitas vezes sob a forma de ocupações irregulares, a população passou a povoar as encostas e margens de cursos de água. Assim, muitos dos problemas atuais urbanos estão correlacionados com situações de risco, como escorregamentos e inundações. Outro fato que cabe destacar é a expansão em direção ao Parque do Rio Doce, com a ocupação ocorrendo dentro dos limites da zona de amortecimento do mesmo. Destaca-se que esta zona foi delimitada tendo por finalidade a preservação do parque, não sendo portanto, adequada sua ocupação por áreas urbanas.

\section{CARACTERIZAÇÃO DO MEIO FÍSICO}

Geologia Segundo CODEMIG (2000), as rochas mais antigas correspondem aos gnaisses do Complexo Mantiqueira (Arqueano), seguido do Granito Açucena (Paleoproterozoico). O primeiro localiza-se na porção central do município, já o segundo se localiza na porção sudoeste da área urbana. Os gnaisses possuem cor cinza e granulação fina e média e possuem estrutura bandada. O Granito Açucena possui granulação média e grossa, cor cinza claro e cinza rosado. As formações mais recentes datam do Período Quaternário, sendo representadas por depósitos sedimentares denominados aluviões e terraços aluviais. Os aluviões são formados por depósitos de sedimentos arenosos, siltosos e argilosos, encontrados, principalmente, às margens do Rio Piracicaba. Os terraços aluviais são depósitos constituídos basicamente por intercalações de areia fina argilosa e argila silto-arenosa nos níveis mais profundos e aterro argilo-siltoso, areno-argiloso, muitas vezes com presença de detritos vegetais e pedregulhos em suas camadas mais superficiais. Esses depósitos sedimentares são de origem fluvial e evidenciam alterações no nível de base dos córregos no município e dos rios Piracicaba e Doce. Essas e outras características evidenciam movimentos neotectônicos, que resultaram no rebaixamento considerável do nível de base dos rios da região (Santos 2008). A figura 3 mostra um extrato do mapa geológico da área do município (CODEMIG 2000). Com relação à cobertura de solos, destaca-se que ocorre na maior parte do município latossolos. Coberturas coluvionares ocorrem em alguns pontos na base de encostas. Depósitos de tálus foram encontrados apenas na porção oeste do município. Nos terraços, a predominância é de solos flúvicos.

Geomorfologia Regionalmente, Timóteo localiza-se na divisa da Zona de Colinas e Cristas - denominada Planaltos Dissecados do Leste de Minas - com a Depressão Interplanáltica do Rio Doce. A estrutura geológica do município propiciou a formação de um relevo formado por serras, e morros alongados, correspondendo a feições do tipo pão de açúcar, como o Pico do Ana Moura. No geral, essas formas de relevo apresentam declividade acentuada, porém as vertentes de alguns morros isolados apresentam-se suaves.

A abordagem dos aspectos geomorfológicos na escala de 1:25.000 permitiu caracterizar quatro unidades geomorfológicas: Terraços Aluviais, Aluviões, Morros e Colinas e Incisões nos terraços. A figura 4 ilustra o mapa de unidades geomorfológicas. Os aluviões representam um relevo plano e encontram-se às 


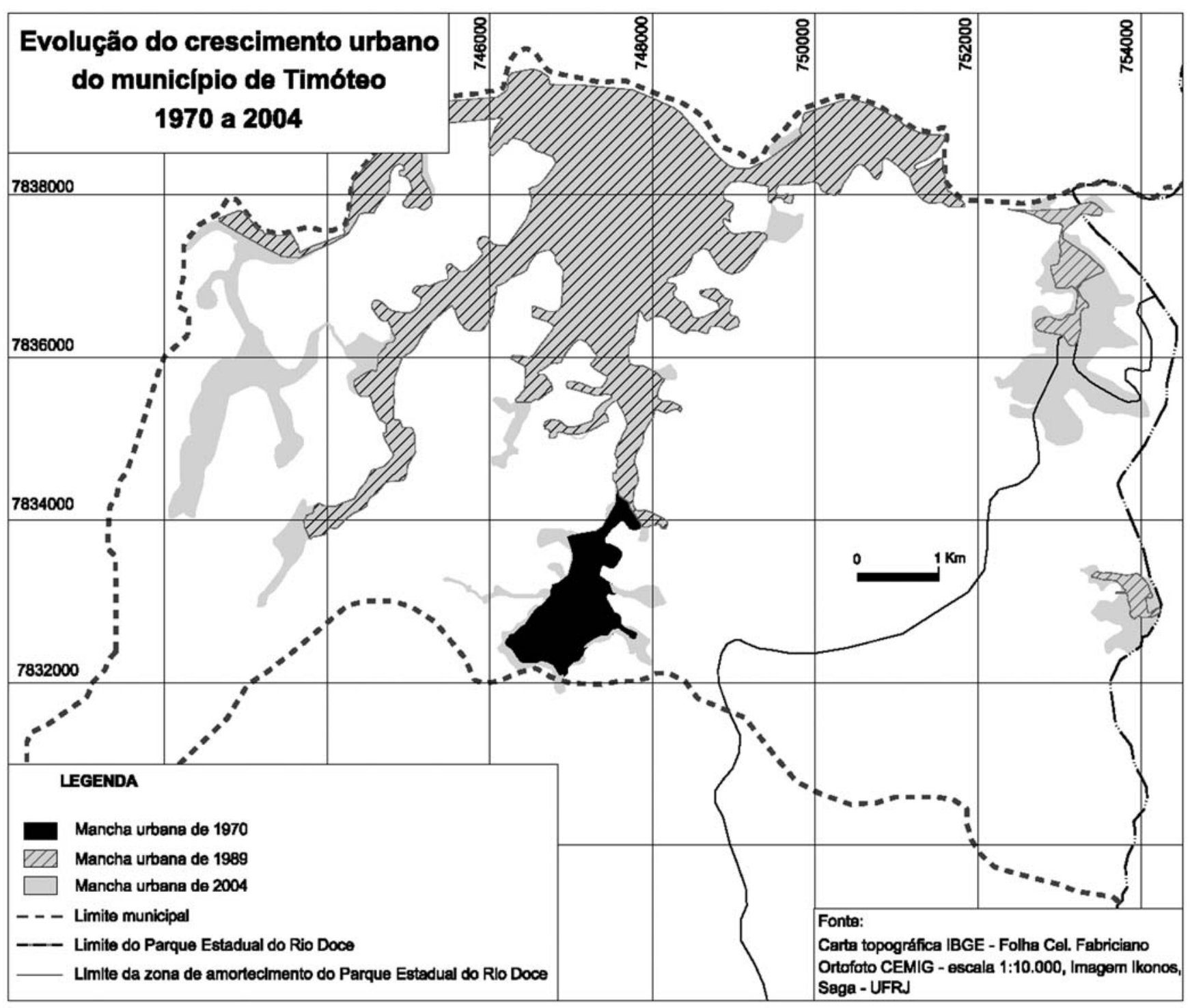

Figura 2 - Mapa da evolução da ocupação no período compreendido entre 1970 e 2004.

margens do Rio Piracicaba, sendo compostos de sedimentos inconsolidados arenosos e areno-argilosos. Apresentam altitudes que variam de 220 a $240 \mathrm{~m}$ e declividades entre 0 a $5 \%$. Os terraços aluviais estão distribuídos na maior parte dos vales do município, sendo inclusive, onde predomina a ocupação urbana, a qual acompanha o relevo plano. Apresenta altitudes variando de 260 a $280 \mathrm{~m}$. São depósitos de origem aluvial com profundidade de $15 \mathrm{~m}$ podendo atingir $20 \mathrm{~m}$ (Mello 1997). Correspondem ao nível de terraço superior (T3) descrito por Meis (1979). Conforme a autora existem quatro níveis de terraços os quais dispõe de três níveis de rampas coluviais: a rampa R3, de maior altitude, pleistocênica, está associada a depósitos provenientes de fluxos de lama e detritos; a rampa R2, intermediária, de idade "neo-pleistocênica", estabelece relação com um terraço de agradação T3, cujos depósitos podem atingir até 35 m de espessura. A rampa R1 inferior, provavelmente do Pleistoceno Superior, exibe colúvios sobrepostos a um terraço de erosão T2. Um terraço T1 e um degrau T0 representam os níveis fluviais holocênicos.

A unidade morros e colinas distribui-se por grande parte da área do município e é a maior unidade mapeada em extensão. Caracterizam-se por serem alongados, sendo que feições do tipo pão de açúcar também ocorrem, como por exemplo, o Pico do Ana Moura. Os declives se encontram acima dos $30 \%$. As litologias desta unidade são o Granito Açucena, Xisto e Biotita Gnaisse. Esta unidade destaca-se por alguns processos geodinâmicos superficiais instalados, como feições erosivas e ravinamentos.

As incisões nos terraços são pequenos vales escavados na unidade terraço e possuem sua origem 


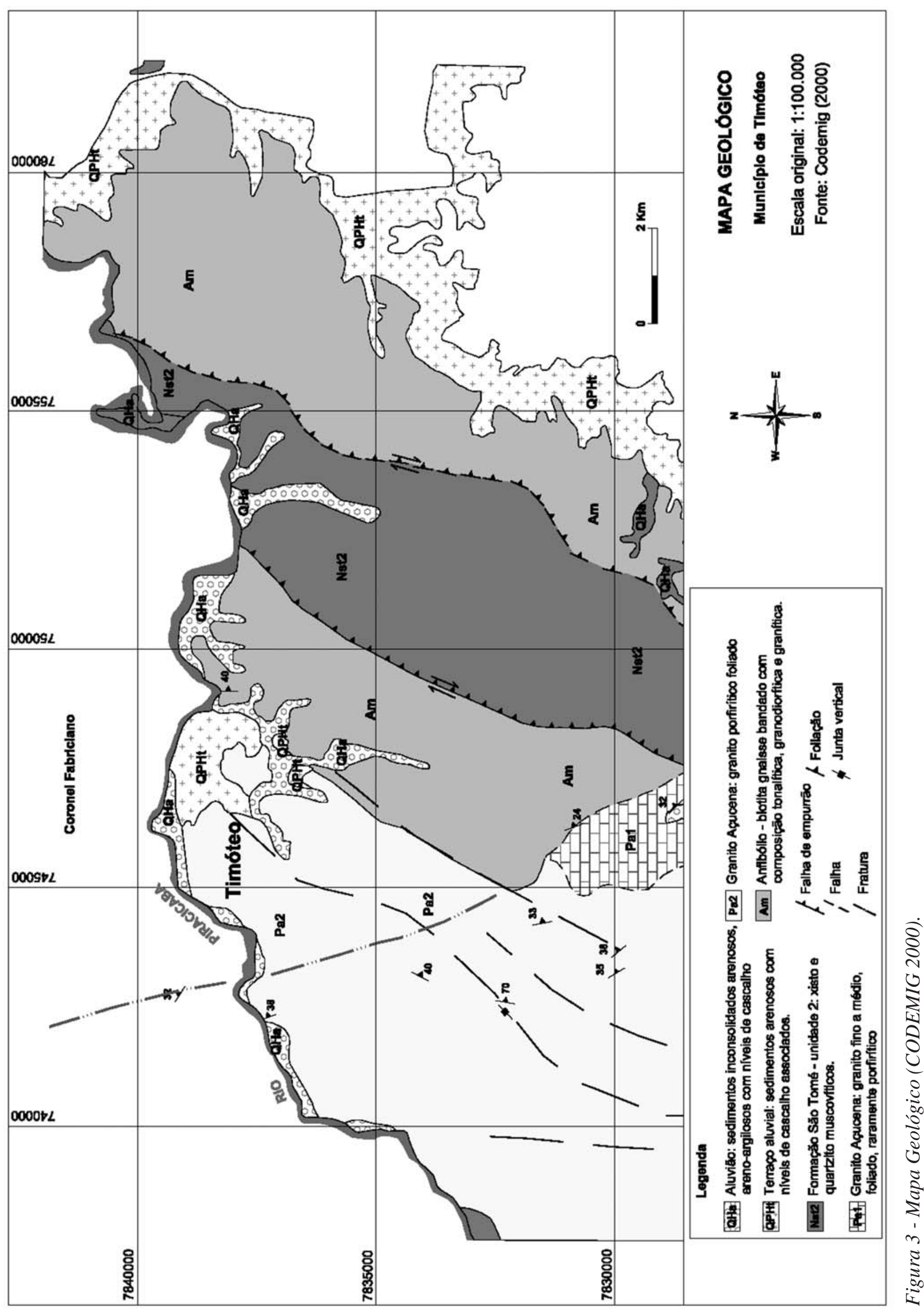




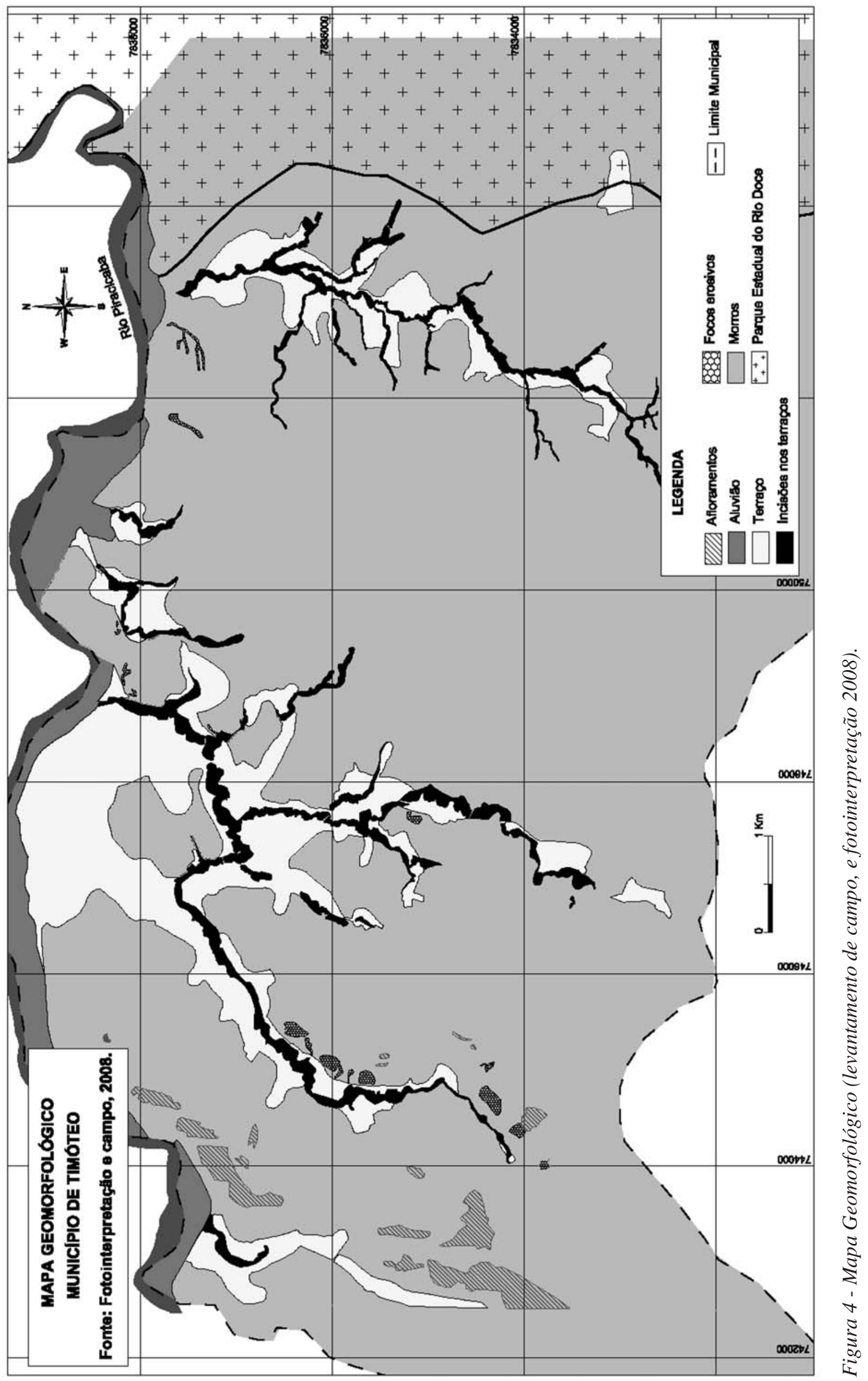


relacionada com a neotectônica ocorrida na região (Santos 2008). Ocorrem sempre cortando as unidades nos terraços, sendo por vezes mais estreitas, outras mais amplas. Neste caso, elas se caracterizam por fundos planos e vertentes íngremes. Em alguns locais a largura atinge aproximadamente $160 \mathrm{~m}$. As de menor extensão têm largura em torno dos $20 \mathrm{~m}$. A composição do material tanto nas vertentes quanto no fundo são areias e argilas aluvionares recentes. Destaca-se que esta unidade está, em muitos pontos, bastante alterada pela ação antrópica, ocorrendo ocupações de diversos padrões em suas margens, aterros, escavações, plantações etc.

Processos Geodinâmicos No município de Timóteo, a análise da susceptibilidade e riscos a processos geológicos foi apoiada em observações e descrições pontuais de campo, fotointerpretação e dados fornecidos pela Prefeitura Municipal de Timóteo. Também foram tomados como base elementos litoestruturais e morfológicos. Como produto, foi gerado um mapa de susceptibilidade aos processos geológicos, representando as áreas mais prováveis de sua ocorrência. As áreas consideradas como susceptíveis a escorregamentos foram as vertentes das incisões nos terraços e as bases das encostas, estando associados a cortes, erosões e ravinamentos. Não foi realizada a hierarquização dos graus de risco em decorrência da indisponibilidade de dados mais precisos sobre as ocorrências.

Os processos erosivos são caracterizados, muitas vezes, pela forte influencia antrópica, e comumente estão associados a episódios de escorregamentos. As características geológico-geotécnicas dos materiais determinam o grau de erodibilidade dos terrenos. A fisiografia da área determina a vulnerabilidade ao escoamento superficial. Observou-se que nas encostas onde o substrato rochoso é o Granito Açucena ocorrem mais processos erosivos que nas demais, onde o substrato rochoso é outro.

Objetivando levantar dados sobre a vulnerabilidade das bacias hidrográficas frente ao uso e ocupação e, principalmente, risco à inundação, foi realizada uma análise morfométrica das bacias do município. O objetivo principal desta análise foi de observar se as bacias possuem tendência à inundação, formação de cursos d'água na ocorrência de chuvas torrenciais e de erosão das margens no caso de córregos não retificados. Foram delimitadas e analisadas nove bacias hidrográficas que possuem ocupação urbana, sendo determinados os seguintes parâmetros: área e perímetro das bacias, número de canais, comprimento total dos canais, altitudes máxima e mínima das bacias, comprimento do canal principal, amplitude altimétrica, fator de forma, densidade de drenagem, densidade hidrográfica, razão de relevo e coeficiente de manutenção.
Das bacias analisadas, duas (Bacias dos córregos Licuri e Limoeiro) apresentaram tendência à inundação, conforme os resultados obtidos para fator de forma. A maioria possui capacidade para geração de cursos d'água no caso de chuvas torrenciais e praticamente todas apontaram baixos índices para densidade de drenagem, o que indica baixa tendência ao escoamento superficial e erosão nas margens. Deste parâmetro excetuam-se as bacias que possuem seu córrego principal retificado.

\section{O PLANO DIRETOR DE TIMÓTEO E A NOVA PROPOSIÇÃO DE ZONEAMENTO O Plano Di-} retor é o instrumento básico da política municipal de desenvolvimento e expansão urbana, que tem como objetivo ordenar o pleno desenvolvimento das funções sociais da cidade e garantir o bem-estar de seus habitantes. É uma lei municipal obrigatória para as cidades com população superior a 20.000 habitantes. Embora a expressão “desenvolvimento e expansão urbana” possa ser entendida de diversas formas, o Plano Diretor tem se constituído basicamente em instrumento definidor das diretrizes de planejamento e gestão territorial urbana, ou seja, do controle do uso, ocupação, parcelamento e expansão do solo urbano. Além desse conteúdo básico, é frequente a inclusão de diretrizes sobre habitação, saneamento, sistema viário e transportes urbanos (Braga 2000).

A elaboração de Planos Diretores tem por objetivo servir como instrumento dos governos municipais para melhor planejar o desenvolvimento da ocupação urbana de seus territórios. Com o Plano são identificadas e analisadas, no município, suas características físicas, suas atividades predominantes e suas vocações, assim como os problemas e potencialidades. Assim, em conjunto com a sociedade, determinar a forma de crescimento a ser promovido, seus instrumentos de implementação e os objetivos a serem alcançados. Nesse sentido, para elaboração do Plano Diretor faz-se necessário o completo conhecimento da realidade do município. Partindo deste pressuposto, assim que é realizado o diagnóstico da situação do município, o governo municipal, de posse de um conjunto informações gráficas, analíticas, qualitativas e quantitativas terá bases concretas para tomada de decisões.

Timóteo teve seu plano diretor aprovado em maio de 2004. De acordo com o Plano, o território do Município divide-se em Zona Rural e Zona Urbana, sendo que esta última subdivide-se da seguinte forma:

1) Área de Proteção Ambiental Serra de Timóteo (APA), que compreende áreas sujeitas a Plano de Manejo, definida pela Lei n. ${ }^{\circ} 2.451$, de 04/06/2003.

2) Zona Urbana de Preservação Relativa (ZP-1), que compreende áreas não parceladas e não ocupadas, 
com declividade entre 30\% (trinta por cento) e $45 \%$ (quarenta e cinco por cento), onde serão admitidos chacreamentos, centros de lazer, clubes recreativos, hotéis-fazenda, acampamentos e afins, bem como atividades de reflorestamento com fins comerciais, desde que obedecidas as normas municipais pertinentes e observada a obrigatoriedade de licenciamento pelo órgão municipal de controle ambiental.

3) Zona Urbana de Preservação Absoluta (ZP2), que compreende áreas consideradas de preservação permanente pelas legislações ambientais da União e do Estado as ocupadas por matas nativas, as de proteção de nascentes e margens de águas correntes e dormentes, as de declividade superior a $45 \%$ (quarenta e cinco por cento) e as de reflorestamento em terrenos com declividade superior a $30 \%$ (trinta por cento), nas quais só serão permitidas atividades relacionadas com as respectivas funções de preservação.

4) Zona Urbana de Interesse Econômico (ZE), que compreende áreas destinadas exclusivamente aos usos comerciais, industriais e de serviços.

5) Zona de Especial Interesse Social (ZEIS), que compreende áreas nas quais há interesse público em ordenar a ocupação, por meio de urbanização e regularização fundiária, ou em implantar ou complementar programas habitacionais de interesse social e que se sujeitam a critérios especiais de parcelamento, ocupação e uso do solo.

6) Zona Urbana de Adensamento Restrito (ZAR), que compreende áreas parceladas ou ocupadas, destinadas a usos urbanos múltiplos: residenciais, comerciais, de serviço e industriais - em que a infraestrutura instalada requer controle do adensamento.

7) Zona Urbana Adensável (ZA), que compreende áreas parceladas ou ocupadas, destinadas a usos urbanos múltiplos - residenciais, comerciais, de serviço e industriais - em que a infraestrutura instalada permite $\mathrm{o}$ adensamento.

O principal problema constatado neste plano é a inobservância de aspectos ligados ao meio físico na determinação do zoneamento. Como consequência, em muitos locais pode haver uma dupla interpretação das indicações das diversas zonas, como por exemplo, a existência de áreas inadequadas a ocupação (incisões nos terraços) dentro da ZAR e ZEIS ou a inclusão de áreas com suscetibilidade a processos geodinâmicos nestas e em outras zonas do plano.

Além deste aspecto, outros pontos podem ser levantados a partir da análise do Plano Diretor. O perímetro urbano, rural e a ZAR não foram demarcados, e a ZAR não está claramente definida. Conforme as informações fornecidas pela prefeitura, a ZAR corresponde a todo o perímetro urbano. Partindo deste pressuposto, em algumas áreas ela se sobrepõe a outras zonas, gerando situações de conflito de uso. Outra questão observada é que não foram definidas no Plano, áreas para expansão urbana cuja delimitação comporta cuidados especiais e possui implicações urbanísticas mais delicadas e, até certo ponto, mais importantes do que a delimitação da própria zona urbana. Destaca-se que devem ser levados alguns critérios urbanísticos, geográficos, geológicos, sociais e econômicos na delimitação de zonas de expansão, item não contemplado no Plano Diretor de Timóteo e isto poderá ocasionar problemas urbanos futuros, que podem ser evitados. Assim, a partir da análise do zoneamento do plano e com a inserção dos resultados dos estudos sobre o meio físico desenvolvidos neste trabalho, é aqui apresentada uma nova proposta de zoneamento, ajustando estes e vários outros pontos contraditórios ou equivocados. A figura 5 mostra a proposta de novo zoneamento apresentada na presente pesquisa.

As questões mais relevantes desta nova proposta são as seguintes:

1) Na porção oeste do município ocorre uma área urbana dentro da ZP2, que é uma zona de preservação absoluta, onde não é permitido esse tipo de uso. Assim, foi proposto transformar essa área urbana em ZAR.

2) A ZE, conforme o Plano Diretor, não permite ocupação urbana; porém ocorre, na porção leste ocupação urbana dentro desta zona. Foi proposto então transformar em ZAR esta área.

3) Dentro da APA Serra de Timóteo, também ocorrem ocupações urbanas tanto na porção norte como na porção leste. Nestas áreas também foi sugerida transformá-las em ZAR.

4) Propõe-se ainda que as incisões nos terraços e os afloramentos sejam delimitados e incluídos no Plano Diretor como zonas inadequadas para ocupação, embora as vertentes das incisões já estejam ocupadas em vários trechos. Assim, seriam impostas restrições à urbanização nos locais ainda não ocupados.

POTENCIAL DE OCUPAÇÃO URBANA A aplicação de um SIG envolve várias etapas, dentre elas a aplicação de modelos de análise espacial destinados à caracterização de ocorrências espaciais. Os modelos de análise espacial em SIG podem traçar cenários, simulações de fenômenos, com base em tendências observadas ou julgamentos de condições estabelecidas. Conforme Moura (2003), o SIG busca tentativas de representação simplificada da realidade, através da seleção dos aspectos mais relevantes, na busca de respostas sobre correlações e comportamentos de variáveis ambientais.

A Análise de Multicritérios se baseia no mapeamento de variáveis por plano de informação e na definição do grau de pertinência de cada plano de informação e de cada um de seus componentes de legenda para a 


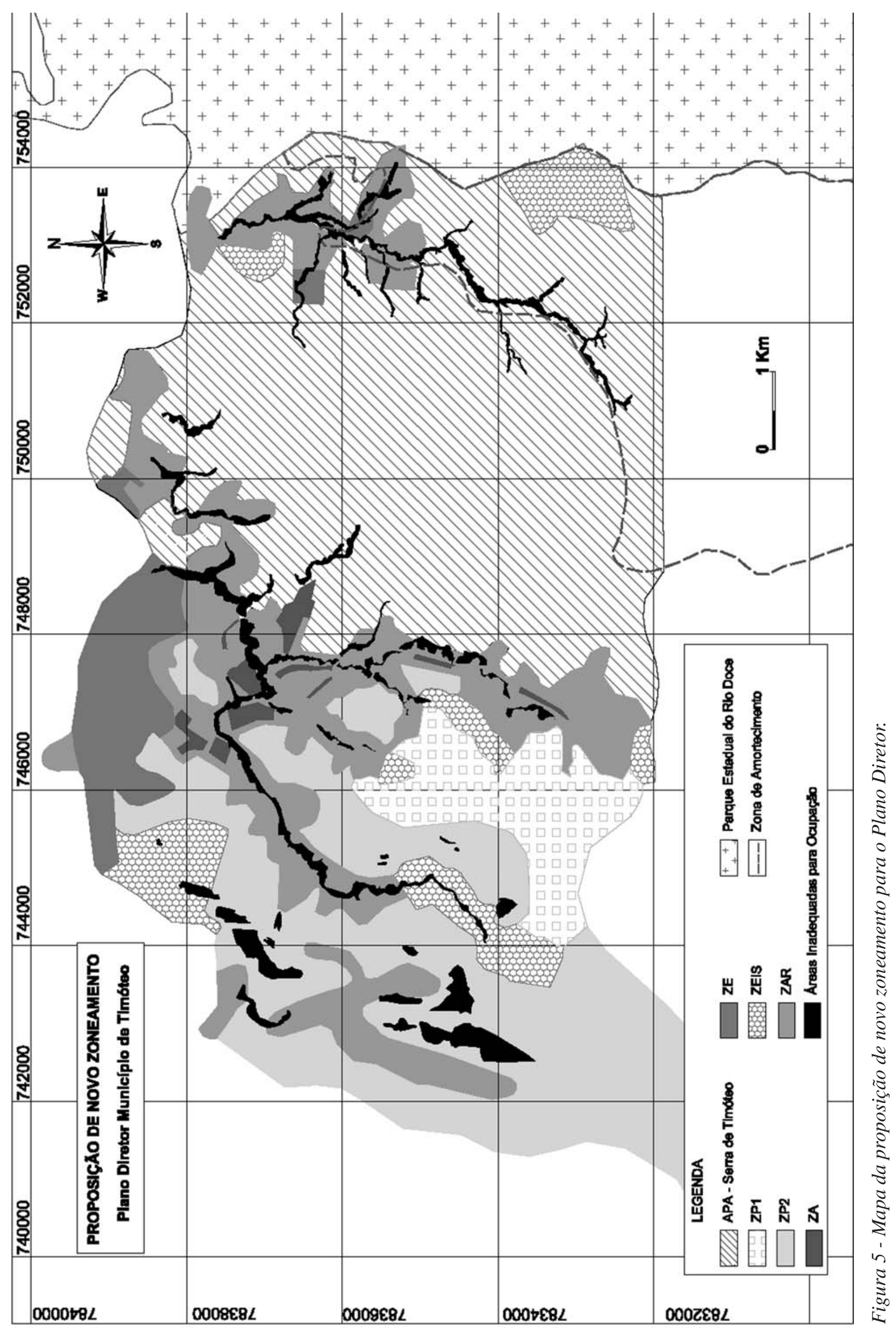


construção do resultado final (Xavier 2001). A matemática empregada é a simples Média Ponderada, mas existem pesquisadores que utilizam a Lógica Fuzzy para atribuir pesos e notas. A ponderação deve ser feita por knowledge driven evaluation, ou seja, por conhecedores dos fenômenos e das variáveis da situação avaliada, ou por data-driven evaluation, que se refere ao conhecimento prévio de situações semelhantes. A Análise de Multicritérios é também conhecida como Árvore de Decisões ou como Análise Hierárquica de Pesos.

Nesta pesquisa, foi realizado um estudo acerca das áreas potenciais para ocupação e expansão urbana, assim como as áreas não propícias. Para realização desta análise, foi utilizado o software SAGA, que foi desenvolvido pelo laboratório de Geoprocessamento da Universidade Federal do Rio de Janeiro voltado para aplicações ambientais. Foi utilizado o módulo do SAGA denominado Avaliação, mas que também é denominado como Árvore de Decisões. O método consiste na atribuição de pesos, que somam $100 \%$ a cada variável componente da análise e, internamente, na atribuição de notas que podem ir da escala de 0 a 10 ou de 0 a 100, para cada componente de legenda da variável. Inumeráveis combinações de dados podem ser realizadas por este esquema (Moura 2003).

Na presente pesquisa optou-se por trabalhar com as variáveis Infra Estrutura Urbana, cujo dado foi retirado do Censo do IBGE de 2000, e Geomorfologia cujos dados foram produzidos pelos autores através de trabalhos de campo e fotointerpretação. Primeiramente foi gerado um mapa Síntese de Infraestrutura Urbana (básica), no qual as variáveis utilizadas para construção foram: coleta de lixo, rede de esgoto e rede de água. Estes dados foram coletados por setor censitário (IBGE 2000). Como o somatório final foi 100, os pesos foram distribuídos conforme grau de importância, como pode ser observado na tabela 1 . As notas foram distribuídas seguindo o critério de que quanto menor a área servida de infraestrutura em questão, menor a nota. O resultado foi a classificação de 1 (baixa infraestrutura) a 10 (alta infraestrutura). A legenda que foi bloqueada significa que não entrou na análise (Tab. 1).

O segundo mapa produzido, que é o principal, foi o de Potencial de Ocupação Urbana (Fig. 6). Para produção do mesmo, foi utilizado o mapa de feições geomorfológicas do município e o mapa Síntese de Infraestrutura Urbana (IBGE 2000), através do mesmo método de Árvore de Decisões. Os pesos e notas foram distribuídos conforme a tabela 2.

O mapa Geomorfológico teve um peso maior que o de Infraestrutura, por se considerar que o meio físico condiciona de forma mais direta a ocupação. O mapa Síntese de Infraestrutura obteve um peso menor, pelo fato de que onde o meio físico possibilita a ocupação
Tabela 1 - Árvore de decisões na avaliação da síntese de infraestrutura urbana.

\begin{tabular}{|c|c|c|c|}
\hline $\begin{array}{l}\text { Legenda da } \\
\text { Avaliação }\end{array}$ & Pesos & $\begin{array}{c}\text { Componente de } \\
\text { legenda }\end{array}$ & Notas \\
\hline \multirow{6}{*}{ Rede de esgoto } & \multirow{6}{*}{$35 \%$} & Área não urbana & Bloqueio \\
\hline & & Baixo & 1 \\
\hline & & Médio a baixo & 3 \\
\hline & & Médio & 5 \\
\hline & & Médio a alto & 7 \\
\hline & & Alto & 10 \\
\hline \multirow{6}{*}{ Rede de água } & \multirow{6}{*}{$35 \%$} & Área não urbana & Bloqueio \\
\hline & & Baixo & 1 \\
\hline & & Médio a baixo & 3 \\
\hline & & Médio & 5 \\
\hline & & Médio a alto & 7 \\
\hline & & Alto & 10 \\
\hline \multirow{6}{*}{ Coleta de lixo } & \multirow{6}{*}{$30 \%$} & Área não urbana & Bloqueio \\
\hline & & Baixo & 1 \\
\hline & & Médio a baixo & 3 \\
\hline & & Médio & 5 \\
\hline & & Médio a alto & 7 \\
\hline & & Alto & 10 \\
\hline
\end{tabular}

Tabela 2 - Árvore de decisões na avaliação do potencial de ocupação urbana.

\begin{tabular}{cccc}
\hline $\begin{array}{c}\text { Legenda da } \\
\text { avaliação }\end{array}$ & Pesos & $\begin{array}{c}\text { Componente de } \\
\text { legenda }\end{array}$ & Notas \\
\hline \multirow{2}{*}{$\begin{array}{c}\text { Mapa } \\
\text { Geomorfológico }\end{array}$} & $60 \%$ & Área não urbana & Bloqueio \\
\cline { 2 - 3 } & & Incisões nos terraços & Bloqueio \\
\cline { 2 - 3 } & & Merraços & 10 \\
\cline { 2 - 3 } & & Afloramentos & 5 \\
\cline { 2 - 3 } Mapa & Aluviões & 1 \\
\hline Infraestrutura & $40 \%$ Baixo & 1 \\
\hline Urbana & & Médio a baixo & 3 \\
\cline { 2 - 3 } & & Médio & 5 \\
\cline { 2 - 3 } & & Médio a alto & 7 \\
\cline { 2 - 3 } & & Alto & 10 \\
\hline
\end{tabular}

(sem riscos), a infraestrutura pode ser criada. Conforme se pode observar no mapa de Potencial de Ocupação Urbana (Fig. 6), as áreas consideradas como de baixo potencial para ocupação foram os aluviões, as áreas carentes de infraestrutura e a APA Serra de Timóteo, 


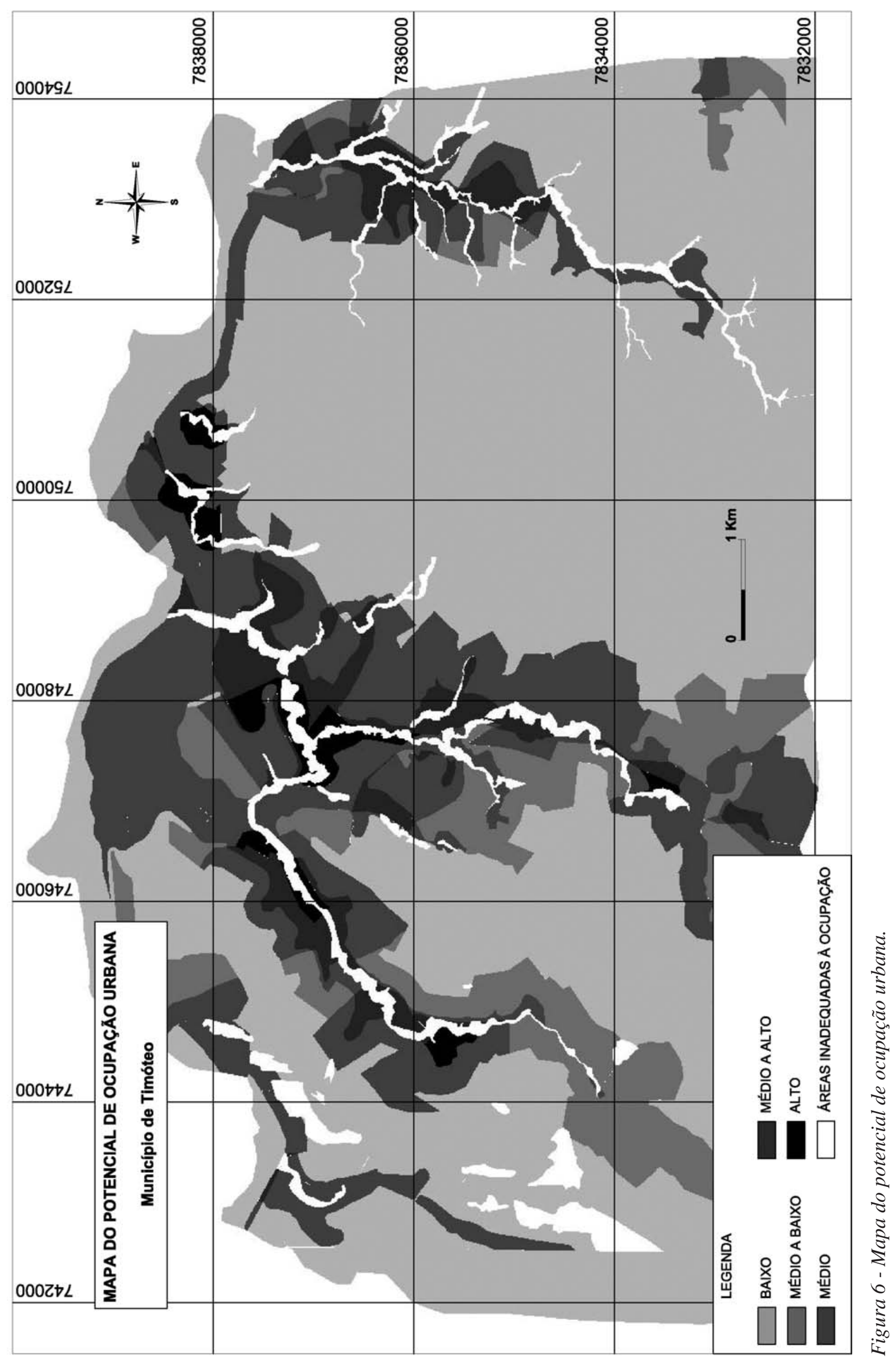


esta última por não permitir ocupação. Como médio a baixo potencial de ocupação, são as áreas com pouca infraestrutura e morros. As áreas com médio potencial são alguns trechos de terraços com pouca infraestrutura e morros com infraestrutura mediana. Como de alto potencial, encontram-se as áreas dos terraços. Estas são atrativas tanto do ponto de vista do meio físico quanto de infraestrutura. As incisões e afloramentos rochosos são áreas inadequadas à ocupação.

CONCLUSÃO Embora muitas cidades já tenham ou estejam elaborando seus planos diretores, o que se observa é que na maioria destes não são considerados tanto no zoneamento como nas diretrizes de ocupação os aspectos relacionados ao meio físico (geologia, geomorfologia e processos geodinâmicos, principalmente). Este fato faz com que os referidos planos tenham inconsistências e conflitos nos respectivos zoneamentos, como observado no presente caso. Apesar de ser ideal a existência de mapeamentos geotécnicos detalhados na elaboração de planos diretores, na maioria dos casos um estudo básico geológico-geomorfológico com abordagem nos processos geodinâmicos ocorrentes (escorregamentos, inundação e erosão, principalmente) pode ser de grande valia para a elaboração desses planos. No caso apresentado, a consideração destes aspectos do meio físico mostrou a necessidade de correção tanto no zoneamento, como também na indicação de normas de procedimentos na ocupação urbana, como a não execução de cortes na base das encostas sem projeto de terraplenagem e contenção e a não ocupação das vertentes das incisões nos terraços, a maioria incluída dentro da Zona de Adensamento no zoneamento oficial. A análise do potencial de expansão urbana é dependente dos dados existentes e do padrão de expansão em cada município, mas pode ser facilmente adaptada e, para sua aplicação, os programas de análise existentes são suficientes para garantir um resultado satisfatório. A proposição de novo zoneamento foi encaminhada à prefeitura Municipal de Timóteo e espera-se que seja discutida na revisão do plano diretor. A metodologia adotada é de simples aplicação, podendo ser utilizada em outras cidades de médio e pequeno porte, na elaboração ou revisão de seus planos diretores.

Agradecimentos Os autores agradecem ao CNPq e FAPEMIG pelo suporte financeiro à pesquisa e concessão de bolsa de estudos.

\section{Referências}

Braga T.M. 2000. Risco e conflito ambiental sob o signo da (mono) indústria: um estudo sobre políticas ambientais na bacia do Rio Piracicaba MG. In: Torres H. \& Costa H.S.M. (orgs.) População e Meio Ambiente: debates e desafios. São Paulo, Ed. do SENAC, p. 327-347.

CODEMIG. 2000. Belo Horizonte (MG): Projeto Leste. $S E-23-Z-D-V$. Belo Horizonte, mapa geológico, escala $1: 100.000$.

Costa G.M. 1995. Vale do Aço: da produção da cidade moderna sob a grande indústria à diversificação do meio ambiente urbano. Tese de Doutorado, Faculdade de Ciências Econômicas, Universidade Federal de Minas Gerais, Belo Horizonte, 291 p.

IBGE - Instituto Brasileiro de Geografia e Estatística 1970. Carta topográfica folha Coronel Fabriciano. SE23-Z-D-V. Belo Horizonte, mapa topográfico, escala $1: 100.000$.

IBGE - Instituto Brasileiro de Geografia e Estatística 2000. Dados demográficos sobre municípios do Rio Doce. Disponível em: http://www.ibge.gov.br. Acessado em: 02/02/2008.

IEF - Instituto Estadual de Florestas. 2005. Unidades de conservação e zona de amortecimento - Parque Estadual do Rio Doce. Belo Horizonte, IEF, Encarte 4, 104 p.

Meis M.R.V. \& Monteiro A.M.F. 1979. Upper Quaternary rampas: Doce river valley. SE Brasilian Plateau. Zeit Geomorph, 23:132-151.

Mello C.L. 1997. Sedimentação Tectônica cenozóica no médio vale do Rio Doce (MG,Sudeste Brasil) e suas implicações na evolução de um sistema de lagos. Tese de Doutorado, Instituto de Geociências, Universidade de São Paulo, São Paulo, 275 p.

Moura A.C.M. 2003. Geoprocessamento na Gestão e Planejamento Urbano. Belo Horizonte, Ed. da Autora, $281 \mathrm{p}$.

Santos C.A. 2008. Análise Morfométrica da rede de drenagem e do relevo do município de Timóteo - MG. In: CBGE, Congresso Brasileiro de Geologia de Engenharia e Ambiental, 12, Anais, 11 p.

Xavier J. 2001. Geoprocessamento para análise ambiental. Rio de Janeiro, Bertrand Brasil, 227 p.

Manuscrito ID 16778

Submetido em 03 de fevereiro de 2010 Aceito em 07 de fevereiro de 2012 